\title{
Protocolo de Controle Glicêmico Hospitalar
}

\section{Hospital Glycemic Control Protocol}

Luizianne Mariano Martins ${ }^{1}$. Manoel Ricardo Alves Martins ${ }^{1}$. Eveline Gadelha Pereira Fontenele ${ }^{1}$. Renan Magalhães Montenegro Junior ${ }^{1}$. Rejane Araújo Magalhães ${ }^{1}$. Paulo Cruz de Queiroz ${ }^{1}$. Renata Carvalho de Alencar ${ }^{1}$. Ana Rosa Pinto Quidute ${ }^{1}$. Catarina Brasil D’Alva ${ }^{1}$. José Ítalo Soares Mota ${ }^{1}$. Ana Flávia Torquato de Araújo Junqueira ${ }^{1}$. Fabiana Maria Lustosa Martins Coretti ${ }^{1}$. Virginia Oliveira Fernandes ${ }^{1}$. Daniel Duarte Gadelha$^{1}$. Manuela Montenegro Dias de Carvalho ${ }^{1}$. Maria Airtes Vieira Vitoriano ${ }^{1}$. Fernanda Nogueira Holanda Ferreira Braga ${ }^{1}$. Rainardo Antônio Puster ${ }^{1}$. Ângela Delmira Nunes Mendes ${ }^{1}$.

1 Hospital Universitário Walter Cantídio (HUWC), Fortaleza, Ceará, Brasil.

\section{RESUMO}

A hiperglicemia é uma complicação frequente, cuja prevalência ocorre em até $38 \%$ dos pacientes internados. Tal condição pode ser decorrente do diabetes previamente conhecido, de estresse responsivo a doenças ou tratamentos associados ou devido ao diabetes somente diagnosticado durante a internação. A presença de hiperglicemia nosocomial associa-se ao prolongamento do tempo de internação, ao aumento da demanda de recursos humanos e custos hospitalares e na piora do desfecho clínico. Diante das dificuldades de manejo da hiperglicemia de pacientes internados, as unidades hospitalares, seguindo as recomendações das sociedades e diretrizes internacionais e nacionais que trata da hiperglicemia do paciente internado, têm desenvolvido protocolos de controle glicêmico hospitalar e criado comissões interdisciplinares para tal fim. O Hospital Universitário Walter Cantídio (HUWCUFC), baseado nas principais diretrizes internacionais e nacionais de tratamento ao diabetes, apresenta o seu protocolo de controle da hiperglicemia numa abordagem multi e interdisciplinar de cuidados ao paciente internado.

Palavras-chave: Glicemia. Cetoacidose diabética. Hiperglicemia. Hipoglicemia. Diabetes. Equipe de assistência ao paciente.

\section{ABSTRACT}

Hyperglycemia is a frequent complication and its prevalence occurs in up to $38 \%$ of hospitalized patients. Such condition may be due to previously known diabetes, stress responsive to associated diseases or treatments or it may due to diabetes only diagnosed during hospitalization. The presence of nosocomial hyperglycemia is associated with prolonged hospitalization time, increased demand for human resources and hospital costs, and worsening of the clinical outcome. In view of the difficulties of managing hyperglycemia in hospitalized patients, hospitals, following the recommendations of international and national societies and guidelines that manage inpatient hyperglycemia, have developed hospital glycemic control protocols and created interdisciplinary commissions for this purpose. The Walter Cantídio University Hospital (HUWC-UFC), based on the main international and national guidelines for diabetes treatment, presents its hyperglycemia control protocol in a multidisciplinary and interdisciplinary approach to inpatient care.

Keywords: Blood glucose. Diabetic ketoacidosis. Hyperglycemia. Hypoglycemia. Diabetes mellitus. Patient care team.

Autor correspondente: Luizianne Mariano Martins, Rua Coronel Nunes de Melo, sem número, Bloco dos ambulatórios, andar superior, Rodolfo Teófilo, Fortaleza, Ceará. CEP: 60430-270. Telefone: +55 85 99603-3900. E-mail: luiziannemartins@yahoo.com.br

Conflito de interesses: Não há qualquer conflito de interesses por parte de qualquer um dos autores.

Recebido em: 29 Jul 2015; Revisado em: 02 Set 2019; Aceito em: 02 Set 2019. 


\section{INTRODUÇÃO}

A hiperglicemia é uma complicação frequente cuja prevalência ocorre em até $38 \%$ dos pacientes internados. ${ }^{1}$ Tal condição pode ser decorrente do diabetes previamente conhecido. Além disso, a hiperglicemia na internação pode decorrer de estresse responsivo a doenças ou tratamentos associados ou devido ao diabetes somente diagnosticado durante esse período.

A presença de hiperglicemia nosocomial associa-se ao prolongamento do tempo de internação, ao aumento da demanda de recursos humanos e custos hospitalares e na piora do desfecho clínico. O diabetes influencia no manejo e no prognóstico dos pacientes internados. $\mathrm{O}$ controle glicêmico e metabólico assegura ao paciente os melhores desfechos no internamento.

Dessa forma, é fundamental pesquisar hiperglicemia durante a internação e instituir o adequado manejo dos pacientes com esse diagnóstico. O Hospital Universitário Walter Cantídio (HUWC-UFC), baseado nas principais diretrizes internacionais e nacionais de tratamento ao diabetes, apresenta o seu protocolo de controle da hiperglicemia numa abordagem multi e interdisciplinar de cuidados ao paciente internado.

\section{CONTEXTUALIZAÇÃO}

O diabetes é desconhecido por até $50 \%$ das pessoas com a doença. ${ }^{2}$ Entre os diabéticos acompanhados no ambulatório, cerca de $25 \%$ a $35 \%$ são hospitalizados a cada ano e até $60 \%$ dos pacientes são reinternados a cada período de quatro anos. O risco relativo de morte é maior entre os pacientes diabéticos, conforme descrito no Quadro 1. No ano de 2018, o custo no estado do Ceará com internações para tratamento de diabetes mellitus e tratamento do pé diabético foi de $\mathrm{R} \$ 1.854 .082,76$, com um custo de $\mathrm{R} \$ 651544,38$ apenas no Município de Fortaleza, conforme os dados no site Tabnet/ Datasus. Esses custos subestimam os custos de internamento em pacientes diabéticos internados por outros motivos.

Diante das dificuldades de manejo da hiperglicemia de pacientes internados, as unidades hospitalares, seguindo as recomendações das sociedades e diretrizes internacionais e nacionais que tratam da hiperglicemia do paciente internado, têm desenvolvido protocolos de controle glicêmico hospitalar e criado comissões interdisciplinares para tal fim, buscando, inclusive, acreditação hospitalar. ${ }^{3}$ Nessa direção, estabelecemos um fluxo geral de avaliação para os pacientes internados que apresentem hiperglicemias, no sentido de assegurar controle glicêmico, metabólico e melhores desfechos clínicos, conforme Figura 1.

Quadro 1. Complicações observadas em diabéticos e risco relativo de morte.

\begin{tabular}{|l|l|l|}
\hline Condição clínica & Complicações observadas entre os diabéticos & Risco relativo de morte \\
\hline Angina/infarto & $\begin{array}{l}\text { Diagnóstico tardio devido à escassez de sintomas } \\
\text { Lesões ateroscleróticas mais extensas e difusas } \\
\text { Piores resultados após trombólise e revascularização }\end{array}$ & 1,4 \\
\hline Insuficiência cardíaca & $\begin{array}{l}\text { Maior incidência e progressão do déficit contrátil } \\
\text { Tendência maior a miofibrose e disfunção diastólica } \\
\text { Maior frequência de isquemia microvascular }\end{array}$ & 3,5 \\
\hline Acidente vascular cerebral & $\begin{array}{l}\text { Maior comprometimento da zona de penumbra } \\
\text { Aumento do risco de transformação hemorrágica } \\
\text { Pior resposta terapêutica à trombólise }\end{array}$ & 2,4 \\
\hline Insuficiência renal & $\begin{array}{l}\text { Maior risco de lesões vasculares e amputação } \\
\text { Perda de acesso (fístula ou cateter) mais frequente } \\
\text { Progressão de retinopatia com uso de eritropoetina }\end{array}$ & $\begin{array}{l}\text { Maior recorrência de infecções } \\
\text { Possível risco de infecções multirresistentes }\end{array}$ \\
\hline Doença arterial periférica & $\begin{array}{l}\text { Maior incidência de infecção, úlceras e gangrena } \\
\text { Maior risco de amputação }\end{array}$ & 2,4 \\
\hline
\end{tabular}

Adaptado de: American Diabetes Association. Diabetes Care in the Hospital. Diabetes Care. 2017;40(Suppl. 1):S120S127. 
Figura 1. Fluxo geral de manejo da hiperglicemia.

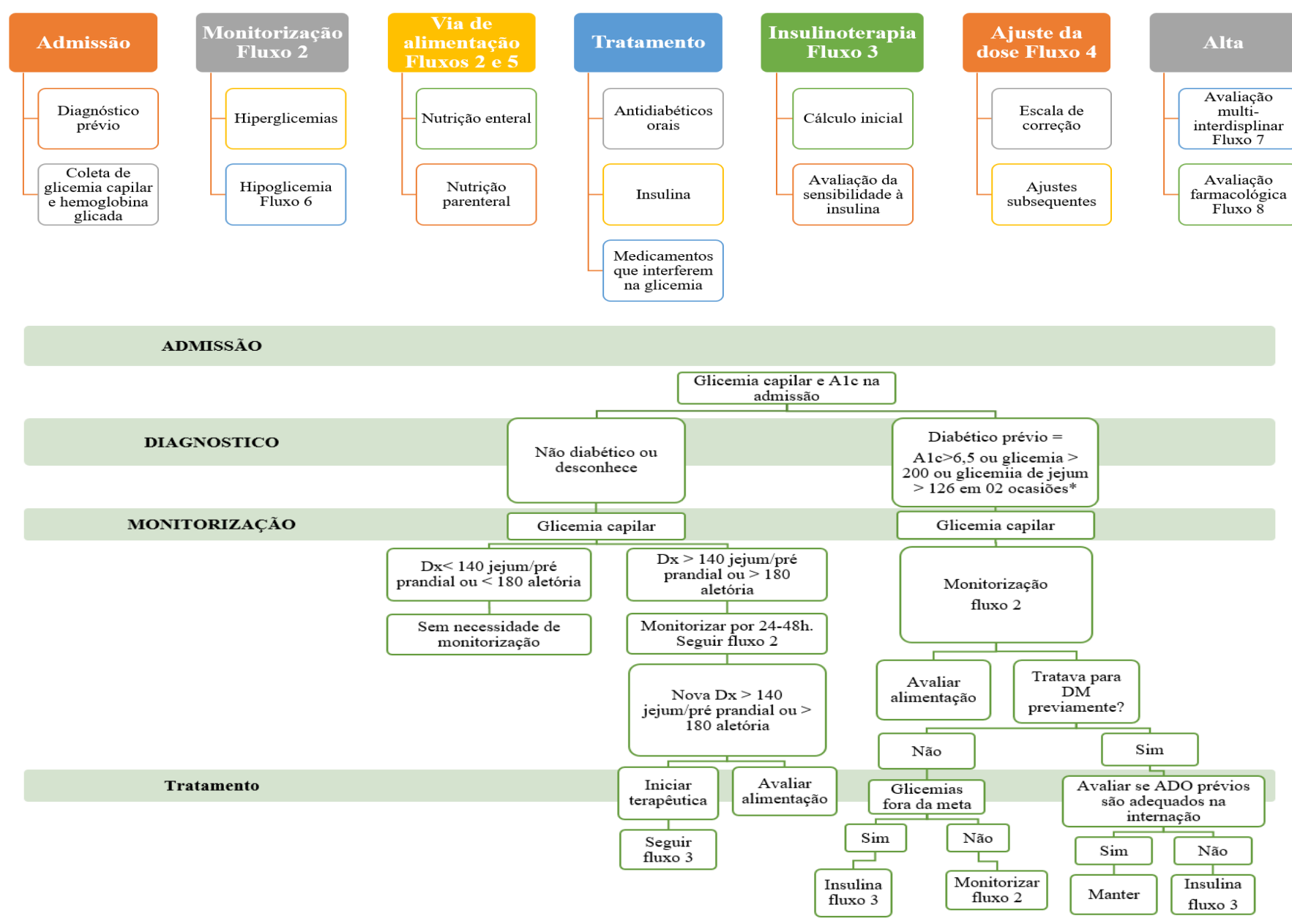

\section{JUSTIFICATIVA}

O Hospital Universitário Walter Cantídio é uma unidade de assistência terciária, voltada para o ensino de Graduação e Pós-Graduação em saúde, com diversos cursos de Residência Médica nas áreas clínicas e cirúrgicas, incluindo Residência em Endocrinologia e Metabologia e cursos de Residência Multidisciplinar em diabetes. Até o presente momento, nenhum protocolo de cuidado à hiperglicemia no paciente internado foi aplicado no HUWC/UFC. O objetivo desse trabalho é instituir um protocolo de controle glicêmico hospitalar, mudando essa realidade e melhorando a segurança do paciente. Visa também definir padrões de conduta, numa perspectiva multi/interdisciplinar, frente ao paciente internado com hiperglicemia com a finalidade de melhorar os desfechos clínicos hospitalares. Dessa forma, esperamos aprimorar os processos de diagnóstico, monitorização, nutrição, cuidados de enfermagem, tratamento medicamentoso, intensificação de educação em diabetes e registros em prontuário médico dos pacientes com hiperglicemias.

\section{CRITÉRIOS DE INCLUSÃO NO PROTOCOLO}

Pacientes adultos internados nas enfermarias clínico e cirúrgicas do HUWC.

\section{CRITÉRIOS DE EXCLUSÃO NO PROTOCOLO}

Pacientes pediátricos e pacientes internados em unidades de terapia intensiva.

\section{DIAGNÓSTICO}

Na admissão, todos os pacientes devem realizar pelo menos um teste de glicemia, além de ter coletada dosagem de hemoglobina glicada (A1C). A hiperglicemia é definida pelo achado de niveis de glicemia capilar em jejum maior que $140 \mathrm{mg} / \mathrm{dl}$ e qualquer valor de glicemia casual maior que $180 \mathrm{mg} / \mathrm{dl} .^{2}$

Ao se estabelecer diagnóstico de hiperglicemia, deve-se classificá-la como:

i) Diabetes mellitus (DM) prévio à internação;

ii) Diabetes mellitus diagnosticado na internação;

iii) Hiperglicemia de estresse.

Segundo a Sociedade Brasileira de Diabetes, hiperglicemia de estresse é caracterizada pela elevação transitória e reversível da glicemia em situações agudas, tais como, trauma, doenças graves, choque, cirurgia, e pelo uso de medicamentos e de nutrição enteral ou parenteral e ocorre em pacientes sem diagnóstico anterior de DM. ${ }^{2}$ 
Nos pacientes internados hiperglicêmicos sem diagnóstico de DM anteriormente conhecido, níveis de A1C iguais ou maiores que $6,5 \%$ estabelecem o diagnóstico de DM prévio. $\mathrm{Na}$ interpretação da hemoglobina glicada (A1C) devese, no entanto, afastar a presença de anemia falciforme ou hemoglobinopatias como fatores de erro.

As metas ou alvos glicêmicos são: glicemia capilar de jejum $<140$ $\mathrm{mg} / \mathrm{dL}^{2}$ e glicemia casual $<180 \mathrm{mg} / \mathrm{dL}^{2}$. Na ausência de diagnóstico prévio de diabetes e/ou hiperglicemia hospitalar (Dx $<140 \mathrm{mg}$ ) dl em jejum ou $>180 \mathrm{mg} / \mathrm{dl}$ ao acaso) não há necessidade de prosseguir com a monitorização, conforme Figura 1.

\section{MONITORIZAÇÃO}

A partir da identificação de hiperglicemia, a frequência e horário da mensuração de glicemias capilares deve ser realizada de acordo com o estado clínico e vias de administração da alimentação do paciente, conforme Fluxo 2, exposto na Figura 2. Os dados da monitorização glicêmica e as doses de insulina administradas devem ser registradas em tabela específica.

\section{CÁLCULO DE DOSE DE INSULINA}

O tratamento da hiperglicemia nos pacientes em estado não crítico é a insulinoterapia, em paralelo à adequação alimentar e a observância do uso concomitante de medicações com efeitos hiperglicemiantes. O esquema de aplicação subcutânea de insulina basal-bolus, que se assemelha a secreção pancreática, é o preferencialmente adotado. ${ }^{4}$

O cálculo da dose de insulina deve considerar o estado clínico, o uso de medicações que afetam a glicemia, a função renal e hepática, o peso corpóreo e a idade do paciente. Esses fatores influenciam o grau de sensibilidade do paciente à insulina que são classificados em normossensíveis, muito sensíveis ou resistentes.
O cálculo inicial da dose de insulina se baseia na sensibilidade a esta medicação, associado à presença de comorbidades, peso do paciente e uso de medicações hiperglicemiantes. A dose diária deve ser dividida em insulina de ação longa ou intermediária (Insulina basal) e ação rápida ou ultrarrápida (Bolus de Insulina), conforme demonstrado na Figura 3, que traduz o fluxo 3 do manejo do paciente hiperglicêmico.

Os pacientes podem necessitar de doses suplementares de insulina por diversos motivos: 1) Se o cálculo da dose inicial foi subestimado pela influência de comorbidades associadas; 2) Se utilizam medicações que afetam a glicemia; 3) Se receberam uma dieta inadequada. Nesse sentido, para proceder aos ajustes no tratamento insulínico é fundamental o rigor nas anotações das glicemias e nos registros de efetivação ou recusa das refeições.

O uso de esquema móvel não deve ser aplicado e, portanto, está proscrito. Os ajustes posteriores na dose de insulina são baseados no perfil glicêmico documentado na ficha de monitorização e na dose suplementar de insulina utilizada no dia anterior.

As doses suplementares são feitas de acordo com a glicemia capilar pré-prandial, conforme as doses descritas na tabela constante na Figura 4, que considera o grau de sensibilidade do paciente à insulina. Os ajustes no dia seguinte devem ser baseados na quantidade de doses suplementares de insulina administradas no dia anterior. Dessa forma, deve ser realizado um adicional correspondente a metade do total da soma das doses suplementares à dose anteriormente prescrita. $\mathrm{Na}$ distribuição desse acréscimo, que pode inicialmente ser fracionada em metade para a dose basal e a outra metade para os bolus pré-prandiais, é também de suma importância considerar a farmacocinética dos diferentes tipos de insulina na análise das tabelas de monitorização. A Figura 5 descreve a farmacocinética das principais preparações existentes.

Figura 2. Fluxo 2 - Monitorização glicêmica segundo perfil de gravidade e nutricional dos pacientes.

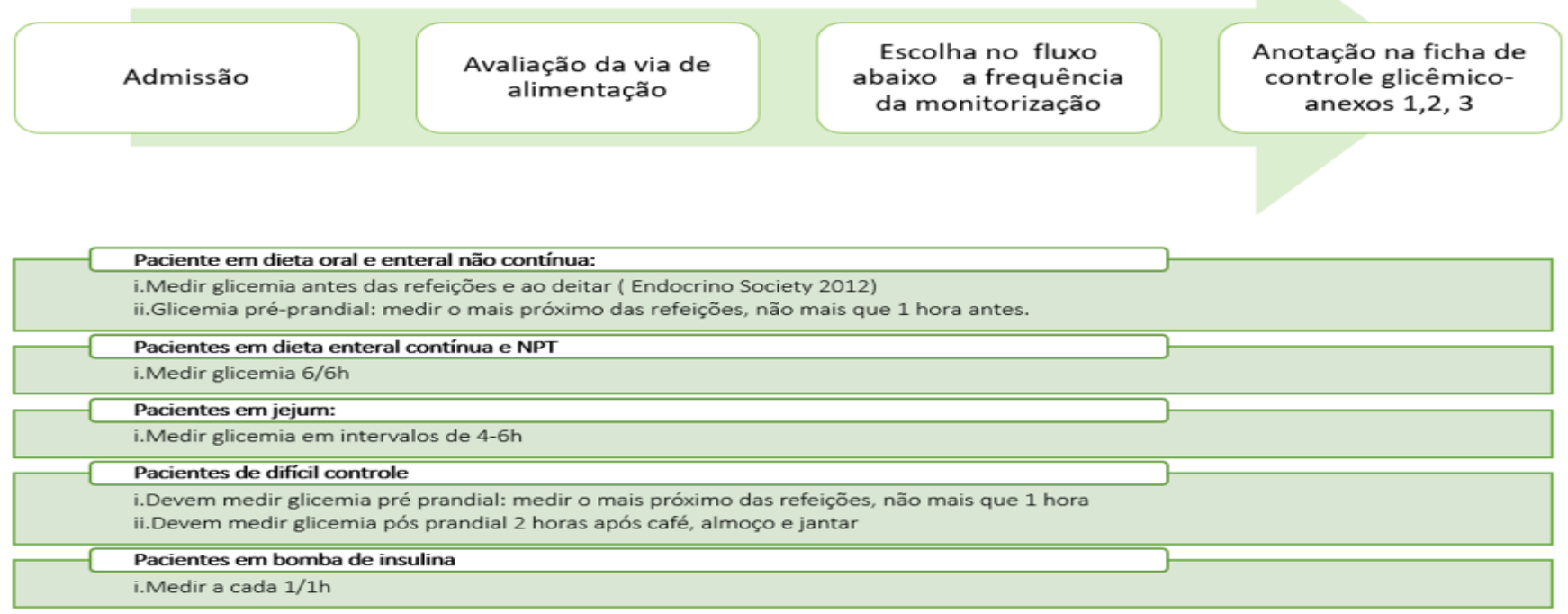


Figura 3. Fluxo 3- Cálculo da dose inicial de insulina.

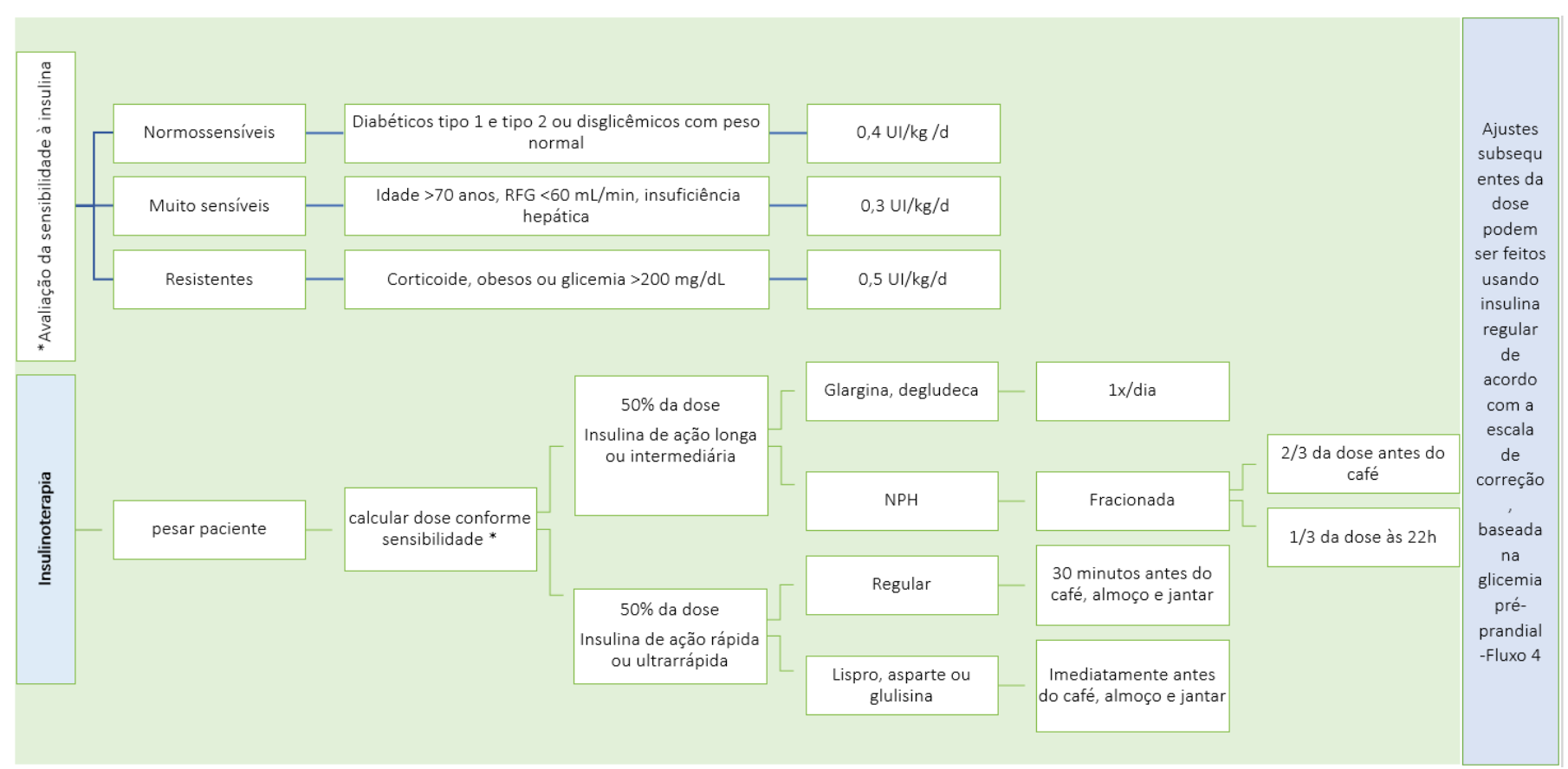

Figura 4. Fluxo 4 - Ajuste de doses - Tabela de doses suplementares e cálculo de ajuste de doses de insulina nos dias posteriores.

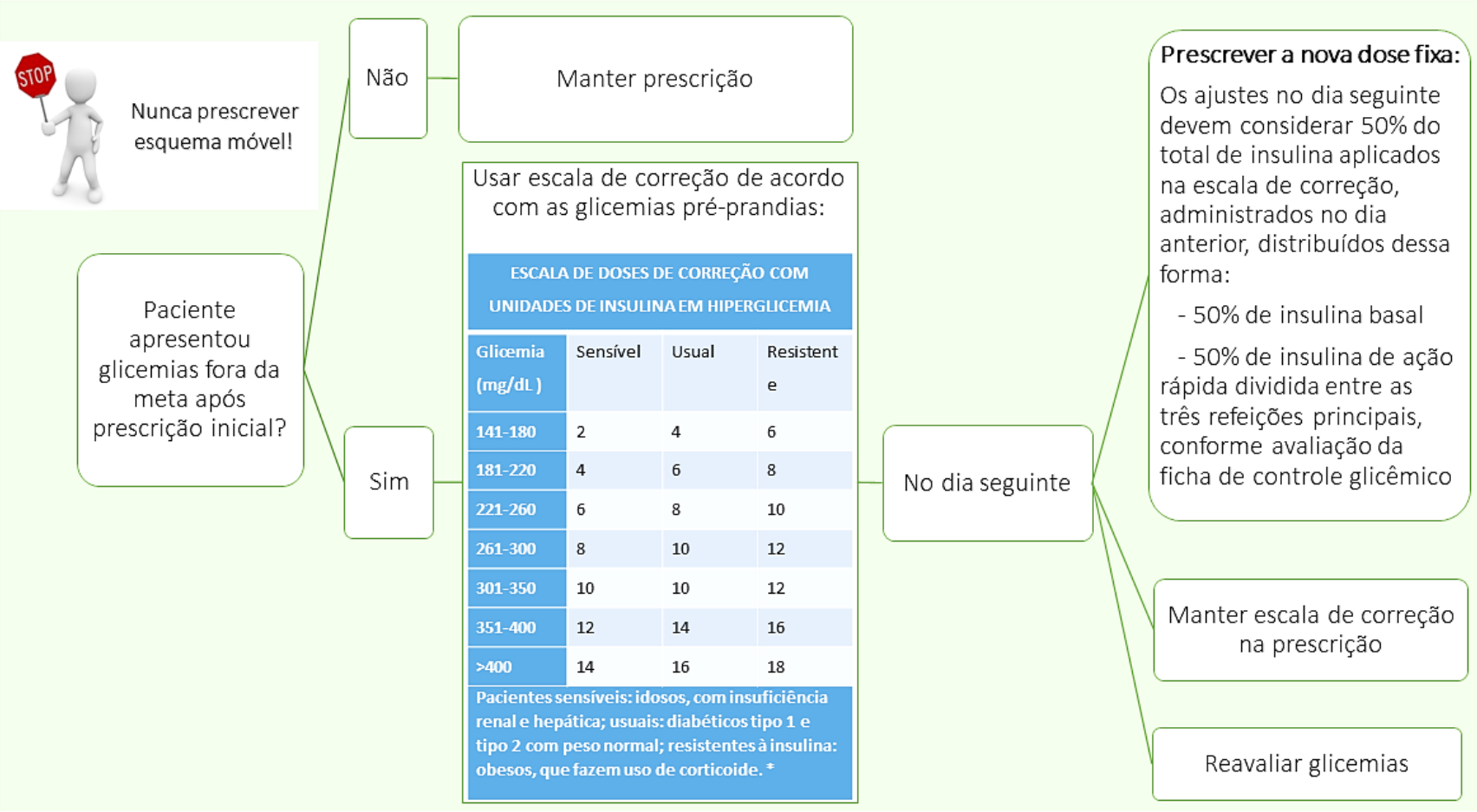


Figura 5. Farmacocinética das principais preparações de insulina.

\begin{tabular}{l|lll} 
Tipo & Início & Pico & Duração \\
\hline Regular (via IV) & imediato & - & $4-5 \mathrm{~min}$ \\
Lispro/glulisina/asparte & $5-15 \mathrm{~min}$ & $1-2 \mathrm{~h}$ & $4-6 \mathrm{~h}$ \\
Regular & $30-60 \mathrm{~min}$ & $2-3 \mathrm{~h}$ & $6-10 \mathrm{~h}$ \\
$\mathrm{NPH}$ & $2-4 \mathrm{~h}$ & $4-10 \mathrm{~h}$ & $12-18 \mathrm{~h}$ \\
Glargina & $2 \mathrm{~h}$ & - & $20-24 \mathrm{~h}$ \\
Detemir & $2 \mathrm{~h}$ & - & $20-24 \mathrm{~h}$ \\
Degludecab & $30-90 \mathrm{~min}$ & - & Maior que 24 h
\end{tabular}

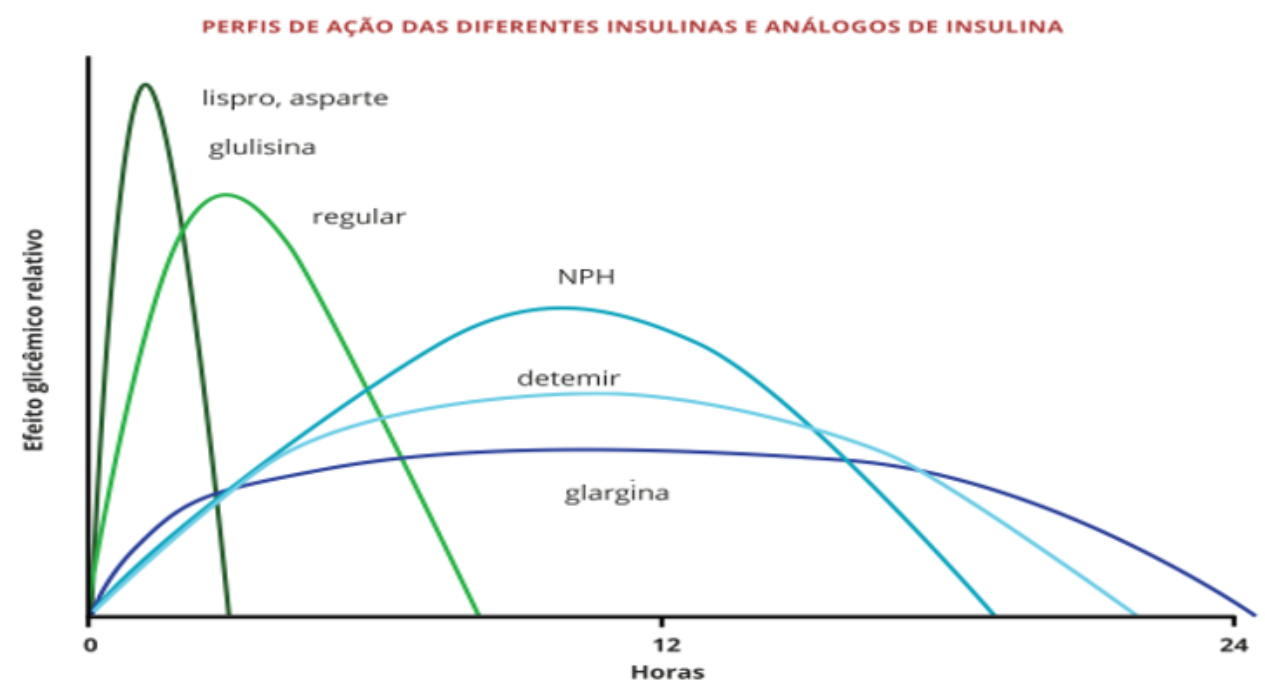

Adaptado de: McMahon GT, Dluhy RG. Intention to treat - initiating insulin and the 4-t study. N Engl J Med. 2007;357(17):1759-61.

\section{VIAS DE ALIMENTAÇÃO}

Recomenda-se que a dieta do paciente seja individualizada e prescrita com o auxílio de profissional especializado em nutrição. ${ }^{5}$

Nos pacientes diabéticos tipo 1 que já adotam o esquema de Contagem de Carboidratos ( $\mathrm{CHO})$, ou mesmo naqueles que estão sob nutrição enteral, uma opção que pode trazer bons resultados no controle glicêmico seria manter ou introduzir a contagem de carboidratos para ajuste da terapêutica.

A forma de cálculo de doses de insulinas e a monitorização glicêmica se modifica a depender do tipo de nutrição enteral (administrada de forma contínua ou descontínua) ou parenteral, conforme o descrito na Figura 6. Outra situação que gera muitas dúvidas é como proceder nos pacientes que estão em jejum por alguma circunstância da rotina de internamento e que têm doses fixas de insulina prescrita. Nesse caso é necessário reduzir a dose basal, de ação intermediaria ou prolongada, conforme a recomendação apresentada na Figura 6.

\section{SITUAÇÕES ESPECIAIS}

\section{Terapia com corticosteroides}

Os corticosteroides podem ser divididos em ação rápida, intermediária ou longa. Eles atuam suprimindo a secreção pancreática de insulina, aumentando a produção de glicose pelo fígado e, principalmente, aumentando a resistência à insulina. Não existem protocolos pré-estabelecidos, mas uma abordagem razoável seria monitorar por 48 horas todos os pacientes com corticoterapia em dose alta e administração de insulina quando necessário. ${ }^{5}$ Os pacientes em uso de corticoide têm necessidade de aumento nas doses de insulina. Essa elevação corresponde a 10-20\% da dose de insulina a cada incremento do corticoide, ${ }^{6}$ mas também é importante lembrar de diminuir a dose de insulina quando houver redução da dose de corticoide. No Quadro 2, especificamos quais as durações de ações dos diferentes tipos de corticoides e a melhor forma de manejo da insulinoterapia. 
Figura 6. Fluxo 5 - Insulinoterapia conforme via de alimentação e jejum.

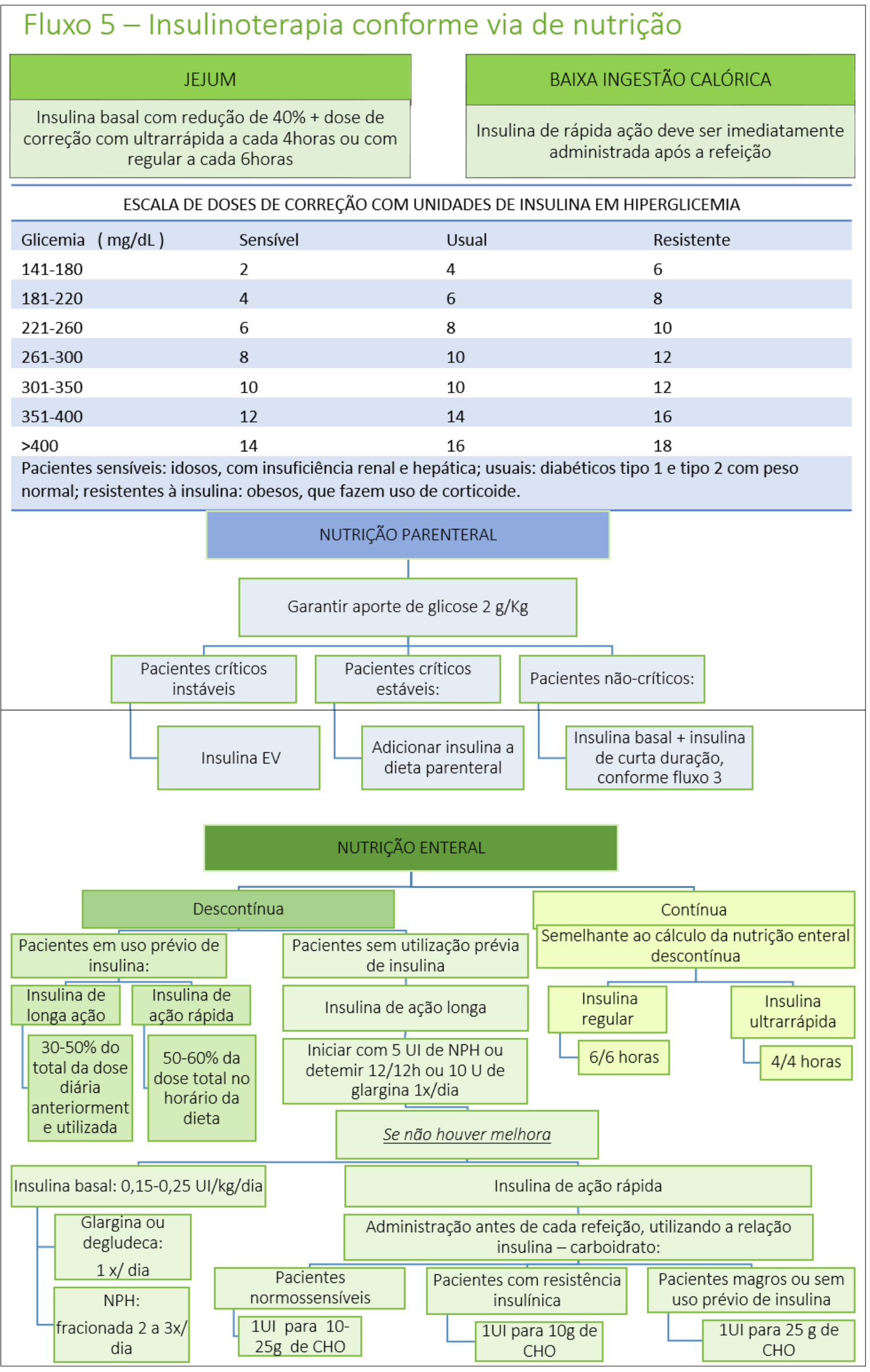


Quadro 2. Efeito dos glicorticoides na glicemia, no metabolismo mineralocorticoideo e manejo.

\begin{tabular}{|c|c|c|c|c|c|c|}
\hline & $\begin{array}{l}\text { Duração da } \\
\text { ação (hs) }\end{array}$ & $\begin{array}{l}\text { Meia vida } \\
\text { plasmática } \\
\text { (min) }\end{array}$ & $\begin{array}{l}\text { Efeito na } \\
\text { glicemia }\end{array}$ & Tratamento & $\begin{array}{l}\text { Potência } \\
\text { mineralocorticoide }\end{array}$ & $\begin{array}{l}\text { Equivalência } \\
\text { de potência } \\
\text { glicocorticoide }\end{array}$ \\
\hline Ação rápida & & & $\begin{array}{l}\text { Jejum e pós } \\
\text { prandial } \\
\text { (múltiplas } \\
\text { aplicações) }\end{array}$ & $\begin{array}{l}\text { Insulinas de ação } \\
\text { rápida corresponderão a } \\
\text { aproximadamente } 70-80 \% \text { do } \\
\text { total }{ }^{\# 1,2}\end{array}$ & & \\
\hline Hidrocortisona & $8-12$ & 90 & & & 0,8 & 20 \\
\hline Cortisona & $8-12$ & 30 & & & 1 & 25 \\
\hline $\begin{array}{l}\text { Ação } \\
\text { intermediária }\end{array}$ & & & Pós-prandial & $\begin{array}{l}\text { Administrar NPH junto com a } \\
\text { dose matutina de corticoide }\end{array}$ & & \\
\hline Prednisona & $24-36$ & 60 & & & 0,25 & 5 \\
\hline Prednisolona & $24-36$ & 200 & & & 0,25 & 5 \\
\hline Metilprednisolona & $24-36$ & 180 & & & 0 & 4 \\
\hline Triancinolona & $24-36$ & 300 & & & 0 & 4 \\
\hline Ação longa & & & $\begin{array}{l}\text { Jejum e pós } \\
\text { prandial }\end{array}$ & $\begin{array}{l}\text { Idealmente utilizar Glargina } \\
\text { ou Detemir }\end{array}$ & & \\
\hline Dexametasona & $36-54$ & 200 & & & 0 & 0,75 \\
\hline
\end{tabular}

\# O esquema de insulina basal-bolus pode ser prescrito da seguinte forma: 0,7 a 1,0 UI/kg/dia, sendo 30\% da dose total de insulina diária como insulina basal e $70 \%$ como insulina prandial.

\#\# As doses diárias de insulina NPH acrescidas ao que já é utilizado ou a pacientes virgens de tratamento são baseadas nas doses de prednisona utilizadas pelo paciente com as seguintes sugestões de doses iniciais: doses de prednisona superiores a $40 \mathrm{mg} / \mathrm{d}$, recomenda-se $0,4 \mathrm{U}$ de insulina NPH/kg: ${ }^{7}$ doses de prednisona de $30 \mathrm{mg} / \mathrm{d}$, utiliza-se insulina NPH 0,3 UI/kg: ${ }^{7}$ dose de prednisona de $20 \mathrm{mg} / \mathrm{dia}$, indica-se 0,2 UI de insulina NPH/ $/ \mathrm{kg}^{7}$ e, dose de prednisona de $10 \mathrm{mg} / \mathrm{dia}$, recomenda-se $0,1 \mathrm{UI}$ de NPH$/ \mathrm{kg} .{ }^{7}$

\section{Pacientes cirúrgicos}

Nos pacientes que irão se submeter à cirurgia, os cuidados do controle glicêmico objetivam atingir a meta de glicemia, mantendo-a entre 110 a $180 \mathrm{mg} / \mathrm{dL}^{8}$ evitar a hipoglicemia, prevenir de cetoacidose e estados hiperosmolare, manter equilíbrio de fluidos e eletrólitos, evitar hiperglicemia acentuada. No Quadro 3, descrevemos as avaliações e os cuidados com o paciente internado no pré-operatório, no dia da cirurgia, durante e após a cirurgia.

\section{Pacientes com insuficiência renal}

Para os pacientes em insuficiência renal, o Quadro 4 especifica os ajustes de doses de insulina de acordo com a taxa de infiltração glomerular.

\section{Pacientes em cuidados paliativos}

O controle glicêmico dos pacientes internados em cuidados paliativos deve ser menos rigoroso para evitar hiperglicemias acentuadas ( $>270 \mathrm{mg} / \mathrm{dL}$ ) ou hipoglicemias. As metas devem ser estabelecidas de acordo com o prognóstico e individualizadas. A interrupção da monitorização e tratamento da hiperglicemia é uma decisão complexa devendo-se analisar o quadro clínico, a percepção da equipe profissional, a política de cuidados paliativos do hospital e o desejo de pacientes e familiares. ${ }^{2}$ É preferível colher glicemia de sangue de acesso venoso periférico. O Quadro 5 descreve as recomendações de cuidados para controle glicêmico de pacientes paliativos segundo expectativa de vida.

\section{Cetoacidose diabética}

A cetoacidose diabética (CAD) é uma complicação grave que pode ocorrer durante a evolução do diabetes mellitus tipos 1 e, mais raramente, em diabetes tipo 2. No Quadro 6, descrevemos as principais características clínicas da CAD, os exames necessários para o seu diagnóstico, e a classificação em leve, moderada e grave, bem como o local de internação e tratamento. Na Figura 7, descrevemos o fluxo de abordagem e tratamento da cetoacidose..$^{10-13}$ 
Quadro 3. Cuidados e avaliações nos pacientes internados com hiperglicemia e indicação cirúrgica.

\begin{tabular}{|c|c|c|c|}
\hline PRÉ-OPERATÓRIO & NO DIA DA CIRURGIA & DURANTE A CIRURGIA & APÓS A CIRURGIA \\
\hline $\begin{array}{l}\text { - Avaliação da A1C }{ }^{2,8} \\
\text { - Controle glicêmico } \\
\text { - Avaliação da função renal }{ }^{8} \\
\text { - } \text { ECG }^{8} \\
\text { - Pacientes usuários de } \\
\text { insulina devem ter } \\
\text { prioridade na programação } \\
\text { das cirurgias no início da } \\
\text { manhã. } \\
\text { - Manter antidiabéticos orais } \\
\text { em geral. } \\
\text { - Suspender antiadiabéticos } \\
\text { orais nos seguintes casos: } \\
\text { o Metformina- } 48 h \text { antes } \\
\text { do uso de contraste }{ }^{2} \\
\text { em casos de cirurgia } \\
\text { com risco de injúria } \\
\text { renal e acidose lática; }{ }^{8} \\
\text { - Sulfoniuréia: idosos, } \\
\text { nefropatas ou risco de } \\
\text { hipoglicemia; }{ }^{2} \\
\text { em } 30 \text { a } 50 \% \text { no dia anterior } \\
\text { ao da cirurgia. } \\
\text { de GLP1- cirurgia } \\
\text { digestiva. }\end{array}$ & $\begin{array}{l}\text { - Antidiabéticos orais e } \\
\text { injetáveis devem ser } \\
\text { suspensos. }{ }^{9} \\
\text { o Avaliar manutenção } \\
\text { da insulina basal } \\
\text { (ação intermediária } \\
\text { ou prolongada com } \\
\text { redução da dose de } 30 \\
\text { a 50\% da anteriormente } \\
\text { prescrita }{ }^{2,9} \text { ) nos } \\
\text { pacientes de difícil } \\
\text { controle e nos pacientes } \\
\text { portadores de DM1. } \\
\text { - Controlar hiperglicemias } \\
\text { com insulina regular, } \\
\text { conforme escala de } \\
\text { correção da figura } 6 \text { - fluxo } \\
\text { 5-jejum. } \\
\text { - Manter aporte de glicose } \\
\text { IV (2g/kg/d) em associação } \\
\text { à reposição de sódio e } \\
\text { potássio. }\end{array}$ & 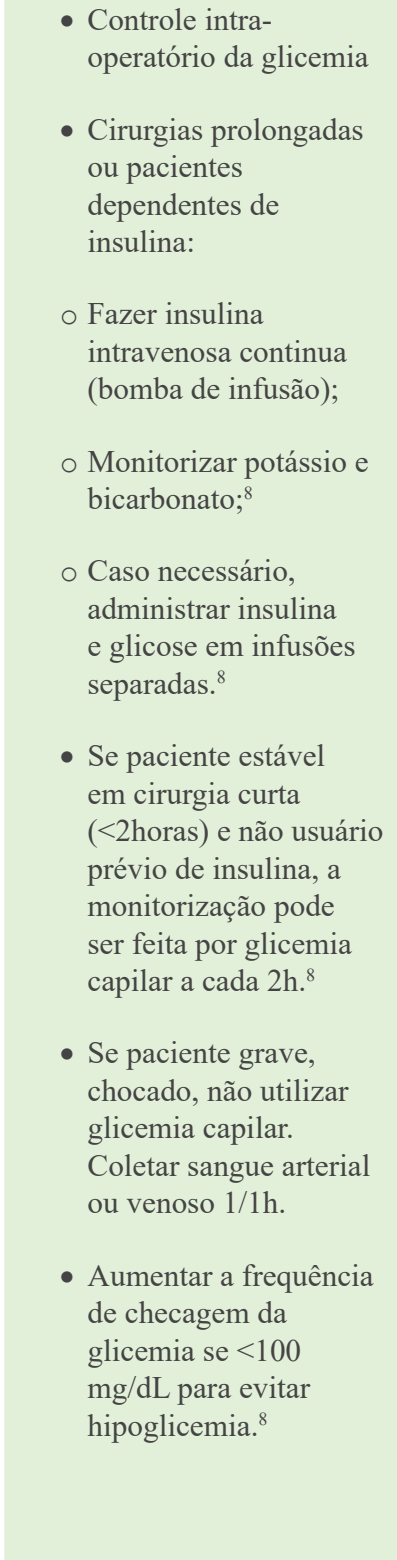 & $\begin{array}{l}\text { - Metformina - não reiniciar } \\
\text { em doentes com insuficiência } \\
\text { renal, insuficiência hepática } \\
\text { significativa ou insuficiência } \\
\text { cardíaca congestiva. } \\
\text { - Sulfoniluréias- iniciar } \\
\text { somente depois que a } \\
\text { alimentação estiver bem } \\
\text { estabelecida. } \\
\text { - Tiazolidinedionas - não } \\
\text { reiniciar se houver } \\
\text { insuficiência cardíaca } \\
\text { congestiva, retenção de } \\
\text { líquidos problemática, ou } \\
\text { insuficiência hepática. } \\
\text { - Se uma infusão de insulina } \\
\text { foi usada, ela deve ser } \\
\text { continuada em pacientes que } \\
\text { não voltam a comer no pós- } \\
\text { operatório. } \\
\text { - Monitorizar glicemia por } \\
\text { 4-6h enquanto dieta zero.. } \\
\text { - Quando reiniciada dieta } \\
\text { sólida oral - trocar por } \\
\text { insulina EV por SC: } \\
\text { o Para insulina de ação } \\
\text { intermediária ou de longa } \\
\text { duração - administrar } \\
2 \text { a } 3 \text { horas antes da } \\
\text { descontinuação; }{ }^{8} \\
\text { ação rápida ou curta- } \\
\text { administrar } 1 \text { ou } 2 \text { horas } \\
\text { antes de interromper a } \\
\text { infusão. } \\
\text { o Para insulina de }\end{array}$ \\
\hline
\end{tabular}

Quadro 4. Ajustes na insulinoterapia, segundo função renal.

\begin{tabular}{|c|c|c|}
\hline TFG $<50 \mathrm{ml} / \mathrm{h}$ & TFG $<10 \mathrm{ml} / \mathrm{h}$ & HEMODIÁLISE \\
\hline \multirow[t]{2}{*}{$\begin{array}{l}\text { Reduzir 25\% da Dose Total de Insulina } \\
\text { (DTI) }\end{array}$} & Reduzir 50\% DTI & $\begin{array}{l}\text { Reduzir a insulina basal, no mínimo em } \\
15 \% \text {, no período pós-diálise }\end{array}$ \\
\hline & & $\begin{array}{l}\text { Evitar insulinas prandiais } \\
\text { e ultrarrápida ação) no } \\
\text { imediatamente anterior à dialise }\end{array}$ \\
\hline
\end{tabular}


Quadro 5. Recomendações no controle glicêmico do paciente internado paliativo segundo expectativa de vida.

\begin{tabular}{|c|c|}
\hline $\begin{array}{c}\text { PROGNÓSTICO ESTÁVEL E SOBREVIDA } \\
\text { MAIOR QUE } 1 \text { ANO }\end{array}$ & $\begin{array}{c}\text { DOENÇAS INCURÁ VEIS EM ESTÁGIO } \\
\text { TERMINAL }\end{array}$ \\
\hline $\begin{array}{l}\text { - Meta glicêmica: } 140-180 \mathrm{mg} / \mathrm{dL} \\
\text { - Evitar hipoglicemia } \\
\text { - Evitar escalas de correção }{ }^{9} \\
\text { - Para pacientes que necessitam de insulina, a metformina } \\
\text { combinada com insulina basal uma vez ao dia é um regime } \\
\text { eficaz e relativamente simples. } \\
\text { - Se a insulina prandial for necessária, ela pode ser administrada } \\
\text { imediatamente após a refeição para melhor adequar o tamanho } \\
\text { da refeição e minimizar a hipoglicemia }{ }^{9} \text {. }\end{array}$ & $\begin{array}{l}\text { - Meta glicêmica: } 110-270 \mathrm{mg} / \mathrm{Dl} \\
\text { - Evitar escalas de correção }{ }^{9} \\
\text { - Para pacientes com diabetes tipo } 2 \text { que não estão mais tomando } \\
\text { nada pela boca, a descontinuação da medicação para diabetes } \\
\text { é razoável }^{9} \\
\text { - Para pacientes com diabetes tipo } 1 \text {, a continuação de uma } \\
\text { pequena quantidade de insulina basal pode prevenir a } \\
\text { hiperglicemia aguda e suas complicaçôes. } \\
\text { o Manter insulina basal com doses compatíveis com as } \\
\text { necessidades mínimas }{ }^{2} \\
\text { o Ajustar a dose } 1 \mathrm{x} / \mathrm{dia}^{2}\end{array}$ \\
\hline
\end{tabular}

Quadro 6. Pontos chaves em cetoacidose diabética.

\begin{tabular}{|c|c|c|c|c|}
\hline & \multicolumn{4}{|c|}{ CETOACIDOSE DIABÉTICA } \\
\hline \multirow[t]{2}{*}{ Diagnóstico } & \multicolumn{2}{|l|}{ Achados clínicos } & \multicolumn{2}{|c|}{ Achados laboratoriais } \\
\hline & \multicolumn{2}{|l|}{$\begin{array}{l}\text { - Poliúria, } \\
\text { - Polidpsia, } \\
\text { - Desidratação, } \\
\text { - Taquicardia, } \\
\text { - Hipotensão, } \\
\text { - Dor abdominal, } \\
\text { - Vômitos, } \\
\text { - Respiração de Kussmaul }\end{array}$} & \multicolumn{2}{|c|}{$\begin{array}{l}\text { - Glicemia plasmática }>250 \mathrm{mg} / \mathrm{Dl} \\
\text { - Cetonemia ou cetonúria } \\
\text { - } \mathrm{PH}<7,3 \\
\text { - } \mathrm{HCO}_{3}<15 \mathrm{mEq} / \mathrm{L}\end{array}$} \\
\hline \multirow[t]{2}{*}{ Avaliação } & \multicolumn{2}{|l|}{ Avaliação clínica } & \multicolumn{2}{|c|}{ Avaliação laboratorial } \\
\hline & \multicolumn{2}{|c|}{$\begin{array}{l}\text { - Avaliar sinais vitais } \\
\text { - Monitorização cardiovascular } \\
\text { - Obter acesso venoso calibroso } \\
\text { - Avaliar sensório } \\
\text { - Avaliar diurese } \\
\text { - Avaliar jejum segundo quadro clínico } \\
\text {-Avaliar fatores precipitantes (infecções, suspensão de } \\
\text { medicamentos, infarto agudo do miocárdio) }\end{array}$} & \multicolumn{2}{|c|}{$\begin{array}{l}\text { - Glicemia } \\
\text { - Gasometria arterial } \\
\text { - Sumário de urina } \\
\text { - Na, K, Cl } \\
\text { - Hemograma completo } \\
\text { - Ureia, creatinina } \\
\text { - PCR }\end{array}$} \\
\hline \multirow[t]{9}{*}{ Classificação } & Parâmetros & Leve & Moderada & Grave \\
\hline & Glicemia mg/dL & $>250$ & $>250$ & $>250$ \\
\hline & $\mathrm{pH}$ arterial & 7,25 a 7,30 & 7,00 a 7,24 & $<7$ \\
\hline & Bicarbonato sérico $(\mathrm{mEq} / \mathrm{l})$ & 15 a 18 & 10 a 14,9 & $<10$ \\
\hline & Cetonúria & positiva & positiva & positiva \\
\hline & Cetonemia & positiva & positiva & positiva \\
\hline & Osmolalidade efetiva & variável & variável & variável \\
\hline & Ânion gap & $>10$ & $>12$ & $>12$ \\
\hline & Nível de consciência & Alerta & Alerta ou sonolento & Estupor ou coma \\
\hline
\end{tabular}

Continua. 
Conclusão.

Quadro 6. Pontos chaves em cetoacidose diabética.

\begin{tabular}{|c|c|c|c|}
\hline \multicolumn{4}{|c|}{ CETOACIDOSE DIABÉTICA } \\
\hline \multirow[t]{2}{*}{ Onde internar } & Observação & UTI & Enfermaria \\
\hline & $\begin{array}{l}\text { - Cetoacidose leve } \\
\text { - Desidratação com diurese } \\
\text { adequada } \\
\text { Manter } 6 \text { a } 12 \mathrm{~h} \mathrm{em} \\
\text { observação }\end{array}$ & $\begin{array}{ll}\text { - CAD grave } & \text {-Desidratação grave } \\
\text { - Acidose com } \mathrm{pH}<7,2 & \text { - Oliguria } \\
\text { - } \mathrm{HCO}_{3}<10 & \text { - Alteração do sensório } \\
& \end{array}$ & $\begin{array}{l}\text { - Demais casos } \\
\text {-pacientes egressos da UTI } \\
\text { por cetoacidose } \\
\text { Danter por } 3 \text { a } 7 \text { dias } \\
\text { até compensação } \\
\text { metabólica }\end{array}$ \\
\hline $\begin{array}{l}\text { Resolução da } \\
\text { cetoacidose }\end{array}$ & \multicolumn{3}{|c|}{$\begin{array}{c}\text { Glicemia entre 200-250 }+2 \text { dos seguintes parâmetros: } \\
-\mathrm{PH}>7,3 \\
-\mathrm{HCO}>15 \\
- \text { Ânion gap }<12\end{array}$} \\
\hline Tratamento & \multicolumn{3}{|c|}{ Seguir fluxograma de manejo, Figura 7} \\
\hline $\begin{array}{l}\text { Transição da } \\
\text { insulina EV para SC }\end{array}$ & $\begin{array}{l}\text { Critérios clínicos } \\
\text { Paciente deve estar: } \\
\text { - Alerta } \\
\text { - Hidratado } \\
\text { - Alimentando-se por via oral }\end{array}$ & $\begin{array}{l}\text { Cálculo da dose } \\
\text { - Nos pacientes virgens de tratamento ou com } \\
\text { causa clínica da descompensação mantida: utilizar } \\
60-80 \% \text { da dose infundida em bomba nas últimas } \\
6 \text { horas, de preferência no período do jejum, e } \\
\text { multiplicar por } 4 \text { para cálculo da dose total diária }{ }^{1} \text {. } \\
\text { - Nos demais, utilizar os fluxos } 3 \text { e } 4 \text {. }\end{array}$ & $\begin{array}{l}\text { Desligar a bomba } \\
\text { - Somente } 2 \text { horas após a } \\
\text { administração de insulina } \\
\text { SC de ação prolongada ou } \\
\text { intermediária } \\
\text { - Se glicemias estáveis: } \\
\text { aumentar o intervalo da } \\
\text { glicemia capilar para } 4 / 4 \mathrm{~h}\end{array}$ \\
\hline
\end{tabular}

Figura 7. Fluxograma de manejo da cetoacidose diabética.

Avaliar sinais vitais. Assegurar via aérea. Obter acesso venoso periférico (abocath > 16). Monitorização cardíaca e da diurese. Coletar gasometria arterial (GAA) e DX. Avaliar K, Ph e HCO3 da GAA. Solicitar HC, Ureia, Creatinina, $\mathrm{Na}, \mathrm{K}, \mathrm{Cl}$, $\mathrm{P}$, cetonemia, glicemia plasmática, PCR, sumário de urina.
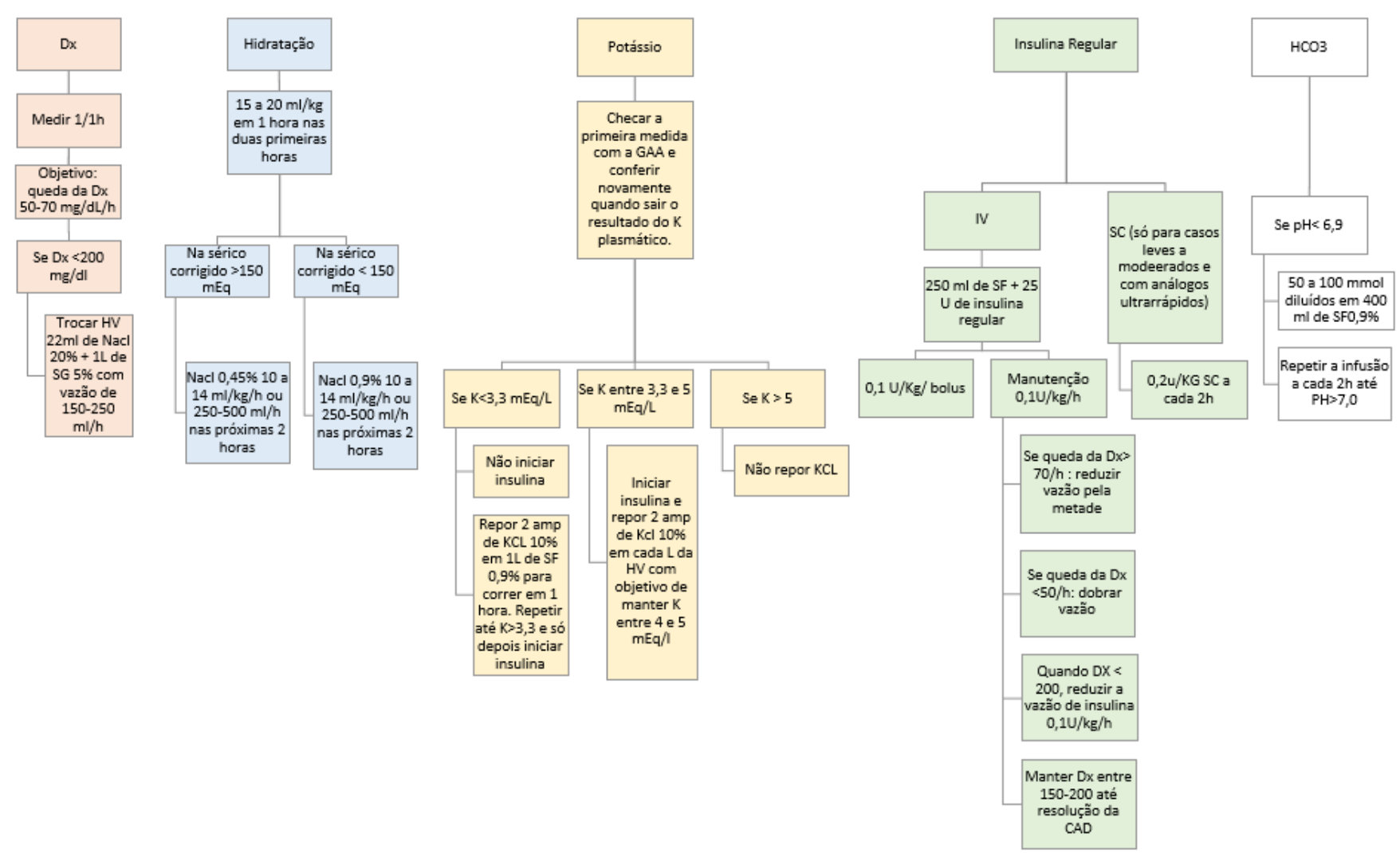


\section{MANEJO DA HIPOGLICEMIA}

A hipoglicemia no paciente internado, em geral, é uma iatrogenia que deve ser eficazmente prevenida. A hipoglicemia é definida como valores de glicemia $<70 \mathrm{mg} / \mathrm{dl}$ e pode ser dividida em níveis de gravidade:

- Nível 1 - concentração mensurável de glicose $<70 \mathrm{mg} /$ $\mathrm{dL}$, porém $\geq 54 \mathrm{mg} / \mathrm{Dl} .^{12}$

- Nível 2 - definida como uma concentração de glicose no sangue $<54 \mathrm{mg} / \mathrm{dL}$. É o limiar no qual os sintomas neuroglicopênicos começam a ocorrer e requer ação imediata para resolver o evento hipoglicêmico. ${ }^{12}$

- Nível 3 - definida como um evento grave caracterizado por funcionamento mental e/ou físico alterado, que requer assistência de outra pessoa para recuperação. ${ }^{12}$

Na ocorrência de hipoglicemia, o tratamento deve ser instituído de forma rápida e adequada. Nos hospitais é comum encontrar a prescrição de reposição endovenosa com sobrecargas desnecessárias de glicose mesmo para pacientes conscientes. Nesses casos, o indicado é fazer a reposição oral. Também é comum a ausência da checagem para avaliar a eficácia das medidas terapêuticas iniciais.

O protocolo de prevenção e tratamento da hipoglicemia visa diminuir a frequência e a magnitude dos episódios, bem como os riscos associados à hipoglicemia. Na Figura 8, descrevemos os principais passos para prevenção e correção da hipoglicemia.

Figura 8. Fluxo 6 - Manejo de correção da hipoglicemia.

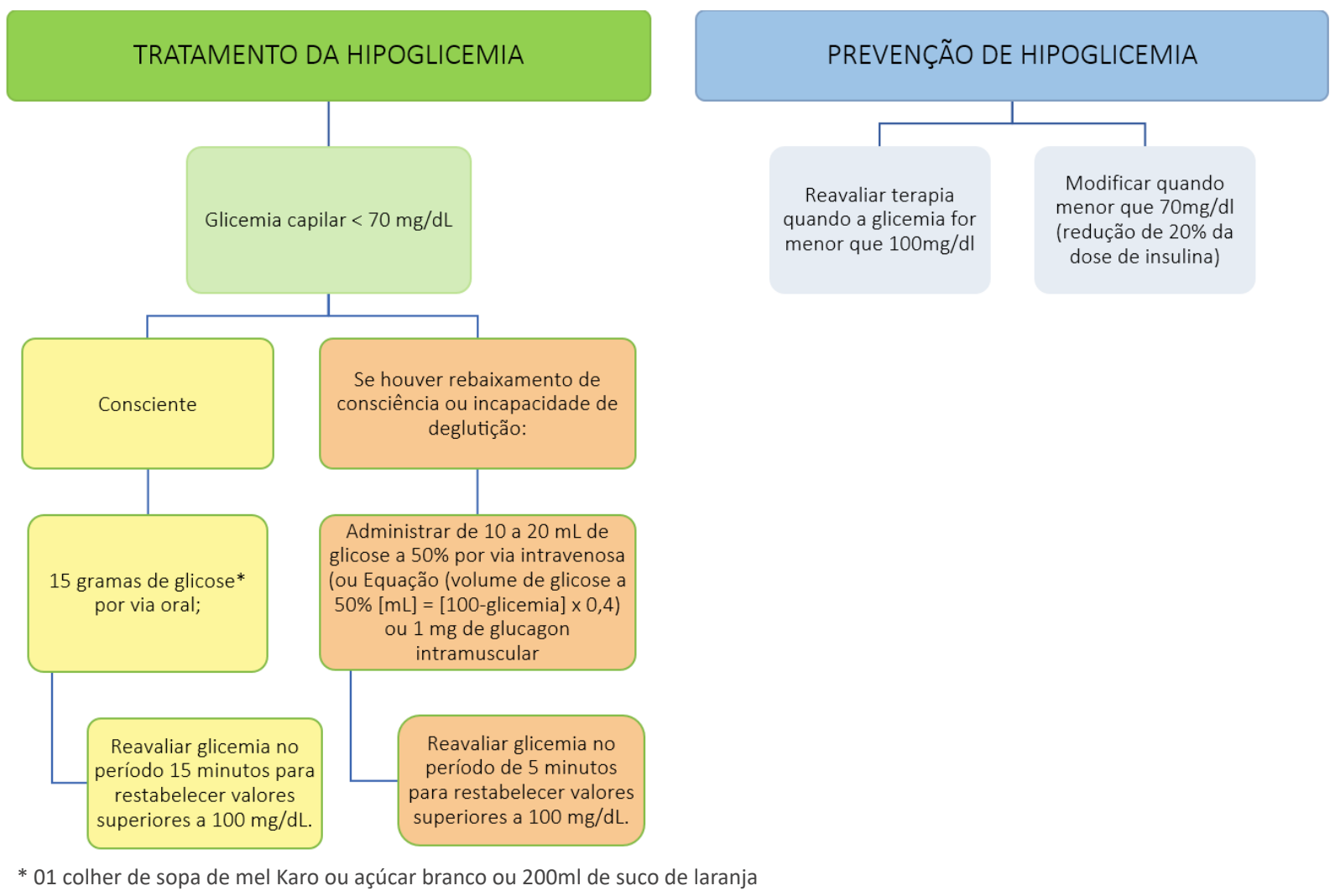

\section{ORIENTAÇÕES PARA ALTA}

No momento da alta é necessário avaliar o controle prévio dos pacientes sabidamente diabéticos; as intercorrências que aconteceram durante o seu internamento; o grau de conhecimento e autogerenciamento em diabetes. Essa avaliação visa melhorar o tratamento, a qualidade de vida dos pacientes e diminuir novas internações.

Os pacientes e cuidadores devem ser habilitados quanto ao uso da técnica de aplicações de insulinas e monitorização glicêmica, terapia nutricional, assim como de reconhecimento e manejo de hipoglicemias. ${ }^{5}$

Desse modo, o trabalho da equipe (Quadro 7), de acordo com o modelo interdisciplinar ou biopsicossocial de atuação, deve facilitar a vivencia da internação de modo a promover nos pacientes e/ou seus cuidadores a educação em diabetes, fortalecendo o compromisso do paciente e de seus familiares.

Os pacientes cujo diagnóstico de diabetes era desconhecido antes da internação e que não necessitem de tratamento hipoglicemiante, após a alta, devem ser encaminhados para o ambulatório de unidade básica de atenção. Uma reavaliação diagnóstica deve ser realizada no intervalo de trinta dias, já que cerca de $60 \%$ desses pacientes terão o diagnóstico de Diabetes mellitus confirmado. ${ }^{6}$

A Figura 9 mostra a adequação de acordo com o controle prévio e a Quadro 8 apresenta as principais classes de antidiabéticos orais e suas precauções e contraindicações. 
Quadro 7. Atribuições da equipe multidisciplinar/interdisciplinar, adaptada da referência 2 para a realidade do HUWC.

\section{Ações do médico}

- Coordenar a assistência multidisciplinar na aplicação do protocolo clínico.

- Orientar os pacientes, seus familiares e a equipe assistencial sobre o plano de tratamento, as metas glicêmicas e as estratégias de controle.

- Solicitar o parecer do endocrinologista quando preciso

- Prescrever medidas de prevenção e tratamento das hipoglicemias.

- Diagnosticar, prevenir e tratar as complicações crônicas.

- Estabelecer um plano educacional no momento da alta do paciente.

- Fazer a transição do esquema intravenoso de insulina para o subcutâneo.

- Orientar o ajuste diário das doses de insulinoterapia plena.

\section{Ações dos técnicos de enfermagem}

- Realizar as glicemias, conforme as orientações do protocolo, no horário adequado.

- Documentar glicemias e doses administradas em impresso próprio.

- Documentar se o paciente encontra-se em jejum ou não no momento da administração de insulina.

- Aplicar a técnica de preparo e administração de insulina.

- Executar prevenção e tratamento de hipoglicemia.

\section{Ações do(a) enfermeiro(a)}

- Acionar o protocolo de manejo glicêmico e se houver dúvidas sobre o protocolo, solicitar o médico plantonista/assistente.

- Aplicar o plano educacional na alta do paciente.

- Educar os pacientes e/ou os cuidadores sobre o manejo apropriado da insulina

- Atentar e aplicar os cuidados adequados ao tratamento com curativos do pé diabético.

- Dominar o timing da insulina pré-prandial e suplementar.

\section{Ações da nutrição}

- Realizar a avaliação e fazer as recomendações nutricionais individualizadas em formulário próprio no prontuário.

- Fornecer as calorias suficientes às necessidades nutricionais e ao controle glicêmico.

- Entregar planilha diária de cardápio com a contagem de carboidratos por refeição a ser anexada ao prontuário.

- Estabelecer um plano de educação nutricional individualizado.

- Aplicar o plano nutricional no momento da alta do paciente.

\section{Ações do farmacêutico}

- Acompanhar o tratamento farmacológico prescrito.

- Orientar sobre farmacocinética, interações medicamentosas e possíveis reações adversas das medicações prescritas.

- Prevenir intoxicações, identificando e notificando as reações adversas aos medicamentos.

\section{Ações da fisioterapia}

- Fazer avaliação fisioterapêutica individualizada.

- Promover treino assistido de marcha ou deambulação.

- Promover educação sobre prática de exercícios físicos adaptados às necessidades do paciente.

- Avaliar a necessidade de palmilhas e órteses para pacientes com polineuropatia diabética.

- Aplicar plano individualizado para alta.

Adaptado de: American Diabetes Association. Diabetes Care in the Hospital. Diabetes Care. 2017;40(Suppl. 1):S120-S127. 
Figura 9. Ajuste de medicações na alta de acordo com o controle prévio do diabetes do paciente, adaptado da referência 2.
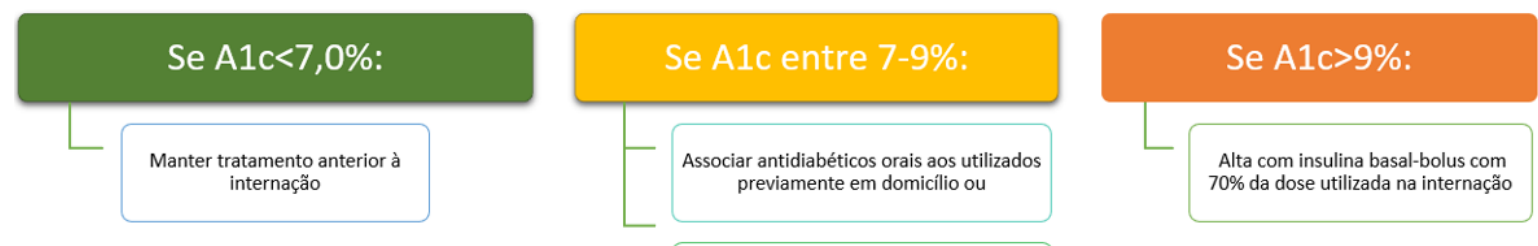

Associar insulina basal bed time

Adaptado de: American Diabetes Association. Diabetes Care in the Hospital. Diabetes Care. 2017;40(Suppl. 1):S120-S127.

Quadro 8. Relação de antidiabéticos orais com estimativa de queda da Alc, contraindicações e precauções na insuficiência renal para análise no momento da alta.

\begin{tabular}{|c|c|c|c|}
\hline MIEDICAÇÃO & VANTAGENS & EVITAR EM: & CORREÇÃO NA IRC \\
\hline Metformina & $\begin{array}{l}\text { - Redução da A1c } 1,5 \text { a } 2 \\
\text { - Redução da GJ: } 60-70 \text { mg/dL } \\
\text { - Diminuição de eventos cardiovasculares } \\
\text { - Prevenção de DM2 } \\
\text { - Melhora do perfil lipídico } \\
\text { - Disponível no SUS }\end{array}$ & $\begin{array}{l}\text { - } \mathrm{ClCr}<30 \text {, } \\
\text { - Paciente que irá submeter- } \\
\text { se a exames contrastados } \\
\text { - Insuficiência hepática } \\
\text { - Insuficiência cardíaca } \\
\text { classe III e IV } \\
\text { - Insuficiência pulmonar }\end{array}$ & $\begin{array}{l}\text { - } \mathrm{ClCr}<45 \text { : } \\
\text { - Usar apenas no paciente que já faziam } \\
\text { uso anterior à internação } \\
\text { - Fazer redução da dose para } 1,0 \mathrm{~g} / \mathrm{dia}\end{array}$ \\
\hline Pioglitazona & $\begin{array}{l}\text { - Redução da A1c 0,5 a 1,4 } \\
\text { - Redução da GJ : 20-30 mg/dL } \\
\text { - Redução do espessamento médio intimal } \\
\text { carotídeo } \\
\text { - Melhora do perfil lipídico } \\
\text { - Redução da gordura hepática } \\
\text { - Rara hipoglicemia }\end{array}$ & $\begin{array}{l}\text { - Insuficiência cardíaca } \\
\text { - Insuficiência hepática } \\
\text { - Osteoporose }\end{array}$ & • Não \\
\hline $\begin{array}{l}\text { Inibidores da } \\
\text { DPP4 (gliptinas) }\end{array}$ & $\begin{array}{l}\text { - Redução da A1c 0,5 a 1,4 } \\
\text { - Redução da GJ: 20-30 mg/Dl } \\
\text { - Rara hipoglicemia }\end{array}$ & - Histórico de pancreatite & $\begin{array}{l}\text { - Ajuste de dose em caso de CLCr }<50 \\
\mathrm{ml} / \mathrm{min} \text {, exceto a linagliptina. } \\
\text { - Saxagliptina,vildagliptina e sitagliptina } \\
\text { são administradas com a metade da dose } \\
\text { usual se TFG for }<50 \mathrm{~m} \ell / \mathrm{min} \text {. } \\
\text { - Alogliptina, o recomendável é } 12,5 \mathrm{mg} / \\
\text { dia para TFG entre } 30 \text { e } 50 \mathrm{~m} \ell / \mathrm{min} \text {; e } \\
6,25 \mathrm{mg} / \text { dia para TFG }<30 \mathrm{~m} / \mathrm{min} \text {. }\end{array}$ \\
\hline $\begin{array}{l}\text { Inibidores do } \\
\text { SGLT2 }\end{array}$ & $\begin{array}{l}\text { - Redução do peso } \\
\text { - Redução da pressão arterial sistólica } \\
\text { - Rara hipoglicemia } \\
\text { - Redução de eventos cardiovasculares e } \\
\text { mortalidade em pacientes com DCV }\end{array}$ & 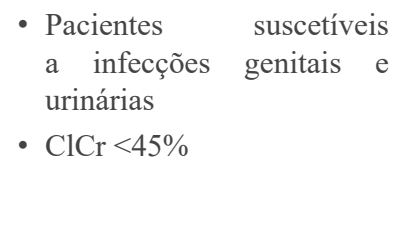 & - Não usar na IRC \\
\hline Analógo da GLP1 & $\begin{array}{l}\text { - Redução do peso } \\
\text { - Redução da pressão arterial sistólica } \\
\text { - Rara hipoglicemia } \\
\text { - Redução da variabilidade da glicose pós- } \\
\text { prandial } \\
\text { - Redução de eventos cardiovasculares e } \\
\text { mortalidade em pacientes com DCV }\end{array}$ & $\begin{array}{l}\text { - Pacientes com histórico de } \\
\text { pancreatite }\end{array}$ & $\begin{array}{l}\text { Exenatide está contra-indicado em } \\
\text { pacientes com } \mathrm{CLCr}<30 \mathrm{ml} / \mathrm{min}\end{array}$ \\
\hline Sulfoniuréias & $\begin{array}{l}\text { - Redução do risco de complicações } \\
\text { microvasculares } \\
\text { - Redução relativamente maior da A1C } \\
\text { - Tem no SUS }\end{array}$ & $\begin{array}{l}\text { - Insuficiência renal } \\
\text { - Insuficiência hepática } \\
\text { - Gestantes } \\
\text { - Logo após IAM }\end{array}$ & - Não usar na IRC \\
\hline
\end{tabular}

Legenda: A1C: hemoglobina glicada; GJ: glicemia de jejum; DM2: diabetes mellitus tipo 2; SUS: Sistema único de Saúde; ClCr: clearance de creatinina; TFG: taxa de filtração glomerular; DCV: doença cardiovascular; IAM: infarto agudo do miocárdio; IRC: insuficiência renal crônica. 


\section{REFERÊNCIAS}

1. Sociedade Brasileira de Diabetes. Parte 10: o paciente hospitalizado. In.: Oliveira JE, Montenegro RM Junior, Vencio S, organizadores. Diretrizes da Sociedade Brasileira de Diabetes 2017-2018. São Paulo: Editora Clannad; 2017 [Acesso em: 02 set 2018]. p. 352-364 Disponível em: https:/www.diabetes.org.br/profissionais/images/2017/diretrizes/ diretrizes-sbd-2017-2018.pdf

2. American Diabetes Association. Diabetes Care in the Hospital. Diabetes Care. 2017;40(Suppl. 1):S120-S127.

3. Arnold P, Scheurer D, Dake AW, Hedgpeth A, Hutto A, Colquitt C, et al. Hospital guidelines for diabetes management and the joint commissionamerican diabetes association inpatient diabetes certification. Am J Med Sci. 2016;351(4):333-41.

4. Umpierrez GE, Hellman R, Korytkowski MT, Kosiborod M, Maynard GA, Montori VM, et al. Management of hyperglycemia in hospitalized patients in non-critical care setting: an endocrine society clinical practice guideline. J Clin Endocrinol Metab. 2012;97(1):16-38.

5. Leal CL, PISI PC, Figueiredo AB, Almeida SC, Moriguti JC. Manejo da hiperglicemia no paciente hospitalizado não crítico. Medicina (Ribeirao Preto). 2010;43(2):134-42.

6. Clore JN, Thurby-Hay L. Glucocorticoid-induced hyperglycemia. Endocr Pract. 2009; 15(5):469-74.
7. Kwon S, Hermayer KL, Hermayer K. Glucocorticoid-induced hyperglycemia. Am J Med Sci. 2013;345(4):274-7.

8. Khan N, Ghali WA, Cagliero E. Perioperative management of blood glucose in adults with diabetes mellitus. Waltham, MA: UpToDate Inc; 2018 [Acesso em: 15 jan 2019]. Disponível em: https://www.uptodate. $\mathrm{com} /$ contents/perioperative-management-of-blood-glucose-in-adultswith-diabetes-mellitus

9. American Diabetes Association. Standards of Medical Care in Diabetes - 2018 Abridged for Primary Care Providers. Clin Diabetes. 2018;36(1):14-37.

10. Vilar L. Endocrinologia clínica. 6. ed. [S.1.]: Guanabara Koogan; 2016.

11. Wajchenberg BL, Lerario AC, Betti RT. Tratado de endocrinologia clínica. 2. ed. [S.1.]: Grupo Gen - AC Farmacêutica; 2014.

12. Gomes PM, Foss MC, Foss-freitas MC. Controle de hiperglicemia intra-hospitalar em pacientes críticos e não-críticos. Medicina (Ribeirão Preto). 2014;47(2):194-200.

13. American Diabetes Association. Diabetes care in the Hospital: Standards of Medical Care in Diabetes-2019. Diabetes Care. 2019;42:S173-81.

\section{Como citar:}

Martins LM, Martins MR, Fontenele EG, Montenegro RM Junior, Magalhães RA, Queiroz PC, et al. Protocolo de Controle Glicêmico Hospitalar. Rev Med UFC. 2019 jul-set;59(3):77-91. 